ARTICLE

https://doi.org/10.1038/s41467-019-09188-9

\title{
In situ spectroscopy-guided engineering of rhodium single-atom catalysts for $\mathrm{CO}$ oxidation
}

\author{
Max J. Hülsey (10 1, Bin Zhang ${ }^{1}$, Zhirui Ma ${ }^{2}$, Hiroyuki Asakura (1) ${ }^{3,4}$, David A. Do ${ }^{5}$, Wei Chen², \\ Tsunehiro Tanaka ${ }^{3,4}$, Peng Zhang (iD ${ }^{5}$, Zili Wu ${ }^{7} \&$ Ning Yan ${ }^{1}$
}

Single-atom catalysts have recently been applied in many applications such as CO oxidation. Experimental in situ investigations into this reaction, however, are limited. Hereby, we present a suite of operando/in situ spectroscopic experiments for structurally well-defined atomically dispersed $\mathrm{Rh}$ on phosphotungstic acid during $\mathrm{CO}$ oxidation. The identification of several key intermediates and the steady-state catalyst structure indicate that the reactions follow an unconventional Mars-van Krevelen mechanism and that the activation of $\mathrm{O}_{2}$ is ratelimiting. In situ XPS confirms the contribution of the heteropoly acid support while in situ DRIFT spectroscopy consolidates the oxidation state and CO adsorption of Rh. As such, direct observation of three key components, i.e., metal center, support and substrate, is achieved, providing a clearer picture on $\mathrm{CO}$ oxidation on atomically dispersed Rh sites. The obtained information are used to engineer structurally similar catalysts that exhibit $\mathrm{T}_{20}$ values up to $130^{\circ} \mathrm{C}$ below the previously reported $\mathrm{Rh}_{1} / \mathrm{NPTA}$.

\footnotetext{
${ }^{1}$ Department of Chemical and Biomolecular Engineering, National University of Singapore, 4 Engineering Drive 4, 117585 Singapore, Singapore.

${ }^{2}$ Department of Chemistry, National University of Singapore, 3 Science Drive 3, 117543 Singapore, Singapore. ${ }^{3}$ Department of Molecular Engineering, Graduate School of Engineering, Kyoto University, Kyoto 615-8510, Japan. ${ }^{4}$ Elements Strategy Initiative for Catalysts \& Batteries (ESICB), Kyoto University, Kyoto 615-8245, Japan. ${ }^{5}$ Department of Chemistry, Dalhousie University, Halifax, NS B3H 4R2, Canada. ${ }^{6}$ Department of Physics, National University of Singapore, 2 Science Drive 3, 117542 Singapore, Singapore. ${ }^{7}$ Chemical Sciences Division, Oak Ridge National Laboratory, Oak Ridge, Tennessee 37831-6133, United States. These author contributed equally: Max J. Hülsey and Bin Zhang. Correspondence and requests for materials should be addressed to N.Y. (email: ning.yan@nus.edu.sg)
} 
S ingle-atom catalysts (SACs), where metal atoms are atomically dispersed on the support, have emerged as a new frontier in catalysis in recent years ${ }^{1-8}$. Many exciting systems were developed, often based on noble metals such as $\mathrm{Pt}^{9-18}$, $\mathrm{Pd}^{19-23}, \mathrm{Rh}^{24-31}$, and $\mathrm{Au}^{32,33}$ but also on earlier transition metals ${ }^{34-39}$ with a number of catalytic applications. However, due to the complex surface structure of most metal oxides and other types of supports, the exact coordination environments of the supported isolated atoms are widely unknown thus hampering mechanistic understanding both experimentally and theoretically.

$\mathrm{CO}$ oxidation is among the earliest ${ }^{40}$ and the most frequently investigated ${ }^{9,12,16,26,40-47}$ reactions for SACs. Mechanistic studies on single-atom catalytic systems for CO oxidation, however, are under intensive debate in the literature ${ }^{9,41}$. Conventional Langmuir-Hinshelwood (L-H), Eley-Rideal (E-R), and Mars-van Krevelen $(\mathrm{M}-\mathrm{vK})$ mechanisms are all discussed. A combination of both $\mathrm{L}-\mathrm{H}$ and $\mathrm{E}-\mathrm{R}$ mechanisms is also proposed where the first molecule of $\mathrm{CO}$ is oxidized in an $\mathrm{L}-\mathrm{H}$ manner via the formation of a peroxide-like intermediate followed by the oxidation of another $\mathrm{CO}$ molecule with the remaining oxygen on the single atom $^{48}$. Another variation of the E-R mechanism suggests the $\mathrm{O}_{2}$ activation promoted by $\mathrm{CO}$ on silver SACs including the simultaneous oxidation of two adsorbed $\mathrm{CO}$ molecules by one $\mathrm{O}_{2}$ molecule from the gas phase ${ }^{49}$. Atomically dispersed Pt supported on $\mathrm{CeO}_{2}$ were shown to follow a water-mediated $\mathrm{M}-\mathrm{vK}$ pathway for the oxidation of $\mathrm{CO}$ via the formation of a carboxylintermediate which can be rapidly dehydrogenated by surface hydroxyl groups ${ }^{43}$. Although thorough kinetic studies on the single-atom catalyzed $\mathrm{CO}$ oxidation are rare, reaction orders towards $\mathrm{O}_{2}$ are normally proposed to be in the range of $0-0.5$ depending on the reaction pathway but have been reported to be 1 in our previous study which hints at an unconventional CO oxidation mechanism on SACs. Those previous investigations leave ambiguity about the exact reaction mechanisms for different SAC systems with some even claiming that SACs exhibit no reactivity in $\mathrm{CO}$ oxidation and the water-gas shift reaction ${ }^{42}$.

The controversial mechanisms proposed in the literature highlight the importance of performing in situ spectroscopic investigation on structurally simple and well-defined SACs to understand the roles of metal, support, and the fate of CO during a full catalytic cycle. Although in situ spectroscopic experiments have proven success in elucidating the structure and active sites of SACs under reaction conditions ${ }^{50,51}$, for $\mathrm{CO}$ oxidation it has so far been primarily limited to $\operatorname{IR}^{42,45}$ and XPS ${ }^{46}$ spectroscopy, tools that only directly or indirectly provide information on the oxidation state of the catalyst. Operando or in situ spectroscopic techniques that provide direct information on both the oxidation state and coordination environment of isolated atoms, such as Xray absorption spectroscopy (XAS), have not yet been employed, let alone the combined use of operando XAS with other in situ techniques. Furthermore, the rational design of SACs with improved catalytic performance based on mechanistic understanding is lacking so far.

A major disadvantage of in situ spectroscopy study is that for spectra measured at an ensemble level an averaged signal of all responsive species is collected, which may hide the information from the real active species and thus be misleading. Only when all species are identical will the spectra reflect accurate information of individual species, and only then the spectra could be conveniently used to reveal structural information and reaction mechanism. We recently reported a SAC system supported on heteropoly acids (HPA) ${ }^{44,52}$, where the coordination environment of each individual atom is clearly defined and investigated by XAS and DFT calculations rendering this catalyst ideal for indepth in situ spectroscopic investigations. An additional benefit of using HPAs is the tunability of the support towards lower or higher redox potential by simply varying the molecular composition of the HPA.

Here, we present operando XAS experiments, corroborated with in situ DRIFTS and XPS analysis, to investigate the active site of a noble metal single-atom catalyst in $\mathrm{CO}$ oxidation, based on a Rh-HPA catalyst that exhibits an onset temperature of $423 \mathrm{~K}$. Extended X-ray absorption fine structure (EXAFS) and X-ray absorption near edge structure (XANES) measurements on the $\mathrm{Rh}$ K-edge are taken in regular periods under air, dilute $\mathrm{CO}$, dilute $\mathrm{O}_{2}$, and then a mixture of $\mathrm{CO}$ and $\mathrm{O}_{2}$ at different temperatures below and above the onset temperature but in a kinetically limited regime (Fig. 1a and Supplementary Figure 1) to reveal the electronic state and coordination environment of the catalyst under reaction conditions. The production of carbon dioxide is monitored online by a mass spectrometer (Supplementary Figure 2). A similar procedure is used for experiments for the operando/in situ W L $\mathrm{III}$-edge (Supplementary Figure 3) XAS, XPS, and DRIFTS studies. Subsequently, three additional HPA-supported rhodium SACs are synthesized, characterized, and tested in the CO oxidation reaction whose eactivity behavior match the predictions by mechanistic understanding.

\section{Results}

Synthesis and characterization of $\mathrm{Rh}_{\mathbf{1}} / \mathrm{NPTA}$. The catalyst synthesis relies on the strong electrostatic adsorption of a rhodium cation on the negatively charged heteropoly acid molecules. To achieve the immobilization of one rhodium atom on a heteropoly acid molecule, a stoichiometric ratio of around 1:4 was chosen for the synthesis. Upon precipitation of the soluble rhodium-HPA adduct, a stable, self-supported SAC $\left(\mathrm{Rh}_{1} / \mathrm{NPTA}\right)$ can be obtained exhibiting good activity in the oxidation of $\mathrm{CO}$. The particle size is around $200 \mathrm{~nm}$ (Supplementary Figure 4) with homogeneously dispersed oxygen, tungsten, rhodium and phosphorus (Supplementary Figure 5). As shown before ${ }^{52}$, heteropoly acids offer a very limited amount of binding sides due to their high symmetry and all rhodium atoms are expected to be located at the same 4-fold hollow site due to its high stability. No Rh-Rh scattering for the $\mathrm{Rh}_{1}$ /NPTA catalyst is observed and the white line intensity is similar to the $\mathrm{Rh}_{2} \mathrm{O}_{3}$ reference sample in the $\mathrm{Rh}$ K-edge EXAFS and XANES spectra (Supplementary Figures 6a and $6 \mathrm{~b}$ ). The first indicates the dispersion of single $\mathrm{Rh}$ atoms whereas the latter relates to positively charged Rh species $(3+)$ at the rest state. Furthermore, the $\mathrm{W}_{\mathrm{III}^{-}}$edge XANES and EXAFS spectra reveal the stability of the phosphotungstic acid after adsorption of rhodium (Supplementary Figures $7 \mathrm{a}$ and $7 \mathrm{~b}$ ). It is expected that the initial catalyst bears a structure as shown in Fig. 1b, where one oxygen molecule is bound to the rhodium single atoms, based on XAFS fitting results ${ }^{44}$.

Oxygen vacancy formation during reductive catalyst treatment. The catalyst was first treated in $\mathrm{CO}$ flow with temperature stepwise-increased from $300 \mathrm{~K}$ to $473 \mathrm{~K}$. The most striking features in the XANES spectra of the Rh SAC after the reductive treatment is the occurrence of two intensive peaks at around 23237 and $23255 \mathrm{eV}$ indicating changes in the structure of the catalyst. A bit less obvious is the formation of a pre-edge feature at around $23220 \mathrm{eV}$ (Fig. 1c and Supplementary Figure 8c). Both changes start to appear at a temperature as low as $323 \mathrm{~K}$, and finish at $373 \mathrm{~K}$, well below the onset temperature of $423 \mathrm{~K}$. Although the appearance of pre-edge features is not often reported for $4 \mathrm{~d}$ and $5 \mathrm{~d}$ metals, a similar pattern has been observed earlier for Ru-based catalysts. Upon distortion of the almost octahedral symmetry at the metal center, the $5 \mathrm{p}$ and $4 \mathrm{~d}$ orbitals are mixing more strongly thus enhancing the intensity of electric dipole forbidden transitions from 1 s to $4 \mathrm{~d}$ orbitals ${ }^{53-55}$. 


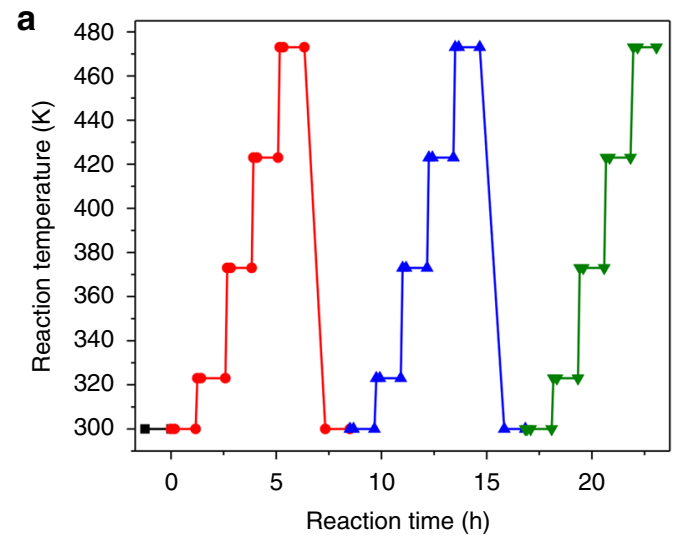

b
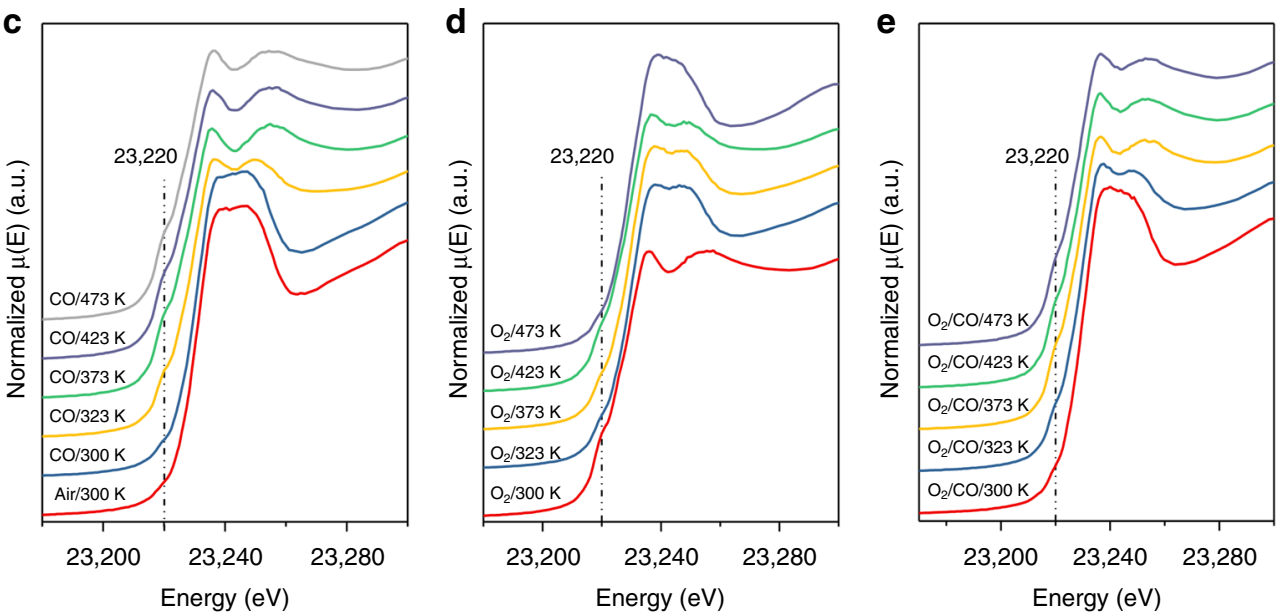

Fig. 1 Course of the operando experiments and correlating operando spectra. a Operando XAS experiments at the Rh K-edge under different atmospheres and reaction temperatures: (black squares) air; (red circles) $5 \% \mathrm{CO} / \mathrm{He}$; (blue triangles) $7 \% \mathrm{O}_{2} / \mathrm{He}$; (green down-pointing triangles) $2.9 \% \mathrm{CO} / 2.9 \% \mathrm{O}_{2} /$ $\mathrm{He}$. b Proposed catalyst structure before exposure to CO with one oxygen molecule bound to Rh. Atom colors: W (gray), O (red), C (black), Rh (blue). Rh $\mathrm{K}$-edge spectra under $\mathbf{c} \mathrm{CO}, \mathbf{d ~} \mathrm{O}_{2}$, and $\mathbf{e} \mathrm{O}_{2} / \mathrm{CO}$ at increasing temperatures (from bottom to top). The dashed lines are highlighting the pre-edge feature and have no physical meaning

In the context of $\mathrm{CO}$ oxidation on a reducible support, this indicates the loss of one oxygen atom in the heteropoly acid support. Subsequently, ab initio XANES prediction on several tetra-, penta-, or hexa-coordinated DFT-optimized structural models were conducted. This method is known to not reproduce intensities very well ${ }^{56}$ but all three key features including the preedge region of the XANES spectrum are predicted at their exact location for the penta-coordinated structure with the oxygen vacancy and two adsorbed $\mathrm{CO}$ molecules (Fig. 1d, e and Supplementary Figure 8d). A simulation for the hexacoordinated structure without oxygen vacancy and two $\mathrm{CO}$ molecules neither yielded a reasonable fit for the pre-edge nor represented the white line features (Supplementary Figure 9a). Although the pre-edge feature is reasonably well captured for the penta-coordinated structure with oxygen vacancy and one bound $\mathrm{CO}$ molecule, the other peaks do not match (Supplementary Figure 9b). After comparison, the structure with two bound CO molecules and the oxygen vacancy (Fig. 2a) was found to give the best alignment between experiment and theory (Fig. 2b). An analysis of the EXAFS scattering contributions revealed a decrease in the first shell and a pronounced increase in the second shell. This can be assigned to scattering contributions from oxygen and carbon monoxide, respectively. EXAFS fitting gives a good overlap between the DFT-optimized structure and the experimental spectra up to a range of around $3 \AA$ around the scattering atoms (Fig. 2d, e). Morlet wavelet analysis of the spectrum after reduction under $\mathrm{CO}$ verified (Fig. 2c) that there was no scattering contribution from rhodium particle or cluster formation. Although the wavenumber for the first shell radial distance is higher $\left(9.0 \AA^{-1}\right)$ than the $7.3 \AA^{-1}$ estimated for $\mathrm{Rh}_{2} \mathrm{O}_{3}$ (Supplementary Figure 10c) it is still significantly below $10.6 \AA^{-1}$ as estimated for rhodium foil (Supplementary Figure 10d). The contribution at $1.2 \AA$ radial distance plausibly comes from a light element such as oxygen. The occurrence of a scattering partner at even lower wavenumber for higher radial distances hint at the adsorption of carbon as a lighter scattering atom similar to a study reported earlier ${ }^{57}$ and thus further corroborates the existence of a CO-bound structure (as shown in Fig. 2a).

Along the $\mathrm{CO}$ treating process, the white line intensity of $\mathrm{Rh}$ is reduced at merely $323 \mathrm{~K}$ and drops entirely at $373 \mathrm{~K}$ (Fig. 1c and Supplementary Figure 8a). Meanwhile, $\mathrm{CO}_{2}$ was detected by the online mass spectrometer as soon as $\mathrm{CO}$ was switched on (Supplementary Figure 2). The trend of the white line intensity change matches well with the intensity change of the pre-edge features. This, together with the fact that $\mathrm{CO}_{2}$ was observed at ambient temperature (without $\mathrm{O}_{2}$ ), highlight the reduction of $\mathrm{Rh}^{3+}$ to $\mathrm{Rh}^{+}$readily occurs on $\mathrm{Rh}_{1} / \mathrm{NPTA}$, which is associated with an oxygen vacancy creation in the support via oxygen transfer from PTA to CO forming $\mathrm{CO}_{2}$ (Fig. 1c). Treatment of the catalyst under $\mathrm{CO}$ correlates to Eq. 1, the conversion of one $\mathrm{CO}$ into one $\mathrm{CO}_{2}$ molecule by the support leaving behind an oxygen 
a

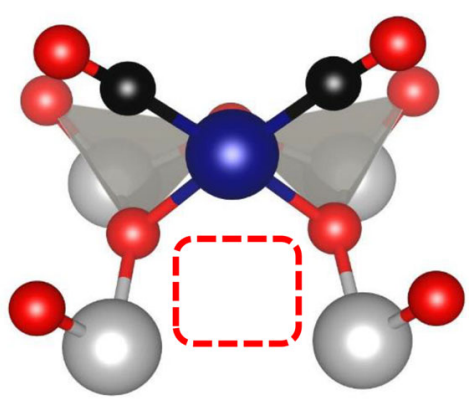

b

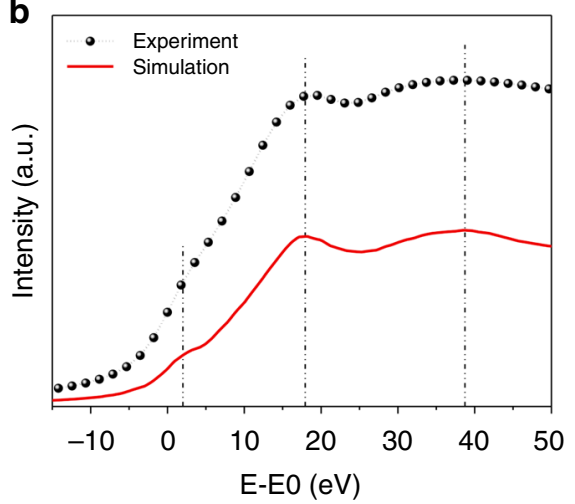

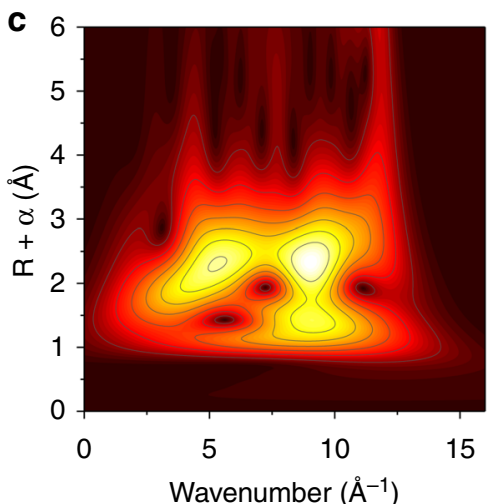

d

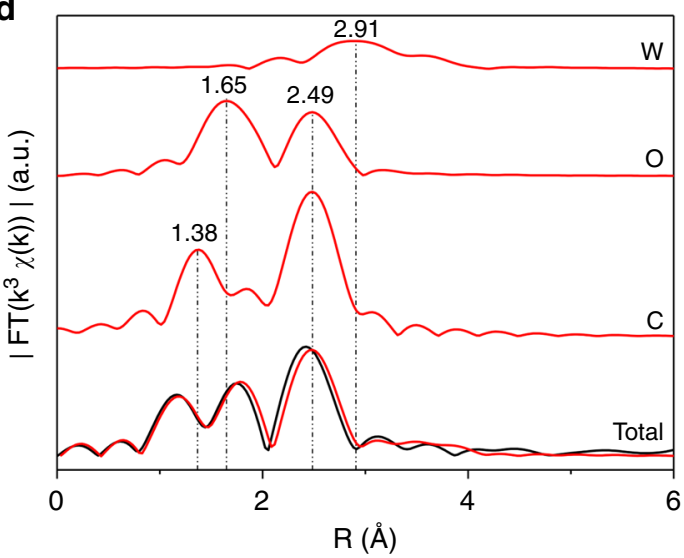

e

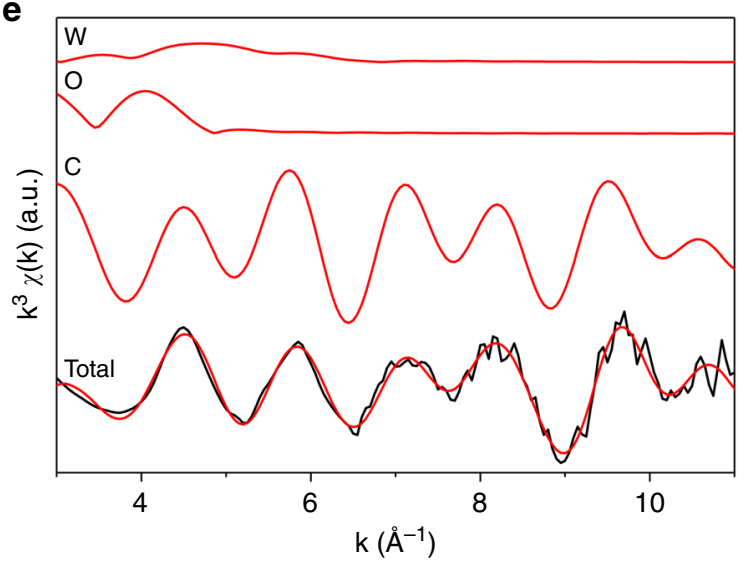

Fig. 2 Spectroscopic evidence for the formation of an oxygen vacancy. a DFT-optimized structure of the catalyst with oxygen vacancy and two bound CO molecules. Atom colors: W (gray), O (red), C (black), Rh (blue). b best fit for the XANES simulation of the catalyst structure depicted in a; c Morlet wavelet transform of the catalyst after treatment under CO. d, e EXAFS analysis of structure (a) in $\mathbf{d} \mathrm{R}$ and $\mathbf{e} \mathrm{k}$ space. Curves from bottom to top are the experimental scattering contributions (black) superimposed with the total fitted scattering contributions, Rh- $\mathrm{C}$, Rh-O, and Rh-W scatterings (all in red)

vacancy (indicated by the dashed circle). The subsequent adsorption of another $\mathrm{CO}$ molecule on rhodium can be expected to be very fast as the calculated adsorption energy of two $\mathrm{CO}$ molecules is high $^{58}$.

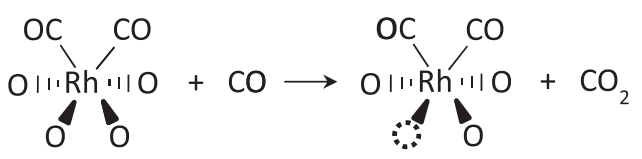

Re-oxidation of the catalyst under oxygen. Re-oxidation of $\mathrm{Rh}$ by $\mathrm{O}_{2}$ to an intermediate level occurs at temperatures as low as $323 \mathrm{~K}$ (Fig. 1d and Supplementary Figure 8b). However, at $423 \mathrm{~K}$ the white line intensity drops again indicating a decrease in oxidation state. This correlates well with the formation of $\mathrm{CO}_{2}$ at the same temperature as shown by mass spectroscopy (Fig. 3c). A comparison of the experimental XANES spectrum at $423 \mathrm{~K}$ with the simulated XANES spectra (Fig. 3b) reveals a significant overlap with the penta-coordinated structure without oxygen vacancy and with a single bound $\mathrm{CO}$ molecule (Fig. 3a). As indicated earlier, the occurrence of the pre-edge feature hints at the loss of centrosymmetry around rhodium, in this case by the removal of one CO molecule. At $473 \mathrm{~K}$, the centrosymmetry is regained by the removal of carbon monoxide in accordance with CO DRIFT spectroscopy under $\mathrm{O}_{2}$ (Supplementary Figure 12). When the release of $\mathrm{CO}_{2}$ is complete, the white line intensity increases again to its maximum indicating that $\mathrm{Rh}$ is in the $3^{+}$ state again (Fig. 1d and Supplementary Figure $8 \mathrm{~b}$ ). The intensity of the pre-edge peak drops significantly at low temperatures (323 and $373 \mathrm{~K}$ ) but increases again during the formation of $\mathrm{CO}_{2}$ upon which the oxygen vacancy seems to be refilled completely (Fig. 1d and Supplementary Figure 8d and Eq. 2 and 3). EXAFS fitting of the structure observed at $423 \mathrm{~K}$ under $\mathrm{O}_{2}$ reveals scattering contributions mainly from the first shell from oxygen but also from higher shell carbon, tungsten, and oxygen scattering (Fig. 3d, e).

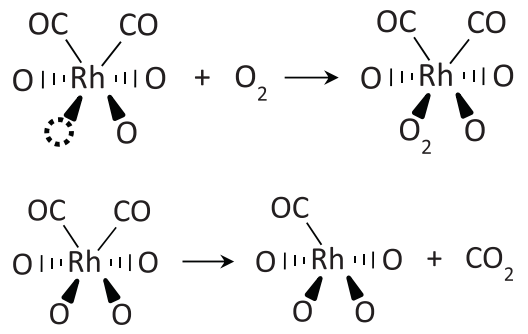

A very similar procedure was chosen for operando XAS experiments at the $\mathrm{W} \mathrm{L}_{\mathrm{III}}$-edge (Supplementary Figure $3 \mathrm{~b}$ ) but with a low $\mathrm{Rh}$ to $\mathrm{W}$ molar ratio, little changes in the XANES and EXAFS are to be expected. Indeed, the white line intensity only changes marginally during the course of the reaction (Supplementary Figures $7 c$ and $7 d$ ) and certain changes in the EXAFS spectra (Supplementary Figure 11a) are probably caused by thermal effects ${ }^{59}$.

Comparing the temperatures at which the catalyst is reduced under $\mathrm{CO}$ and re-oxidized under $\mathrm{O}_{2}$ provides insights into the relative rates of individual steps in a catalytic cycle. When exposed to $\mathrm{CO}, \mathrm{Rh}$ is partially reduced even at $323 \mathrm{~K}$ and fully reduced at $373 \mathrm{~K}$. In accordance with that is the oxygen vacancy 

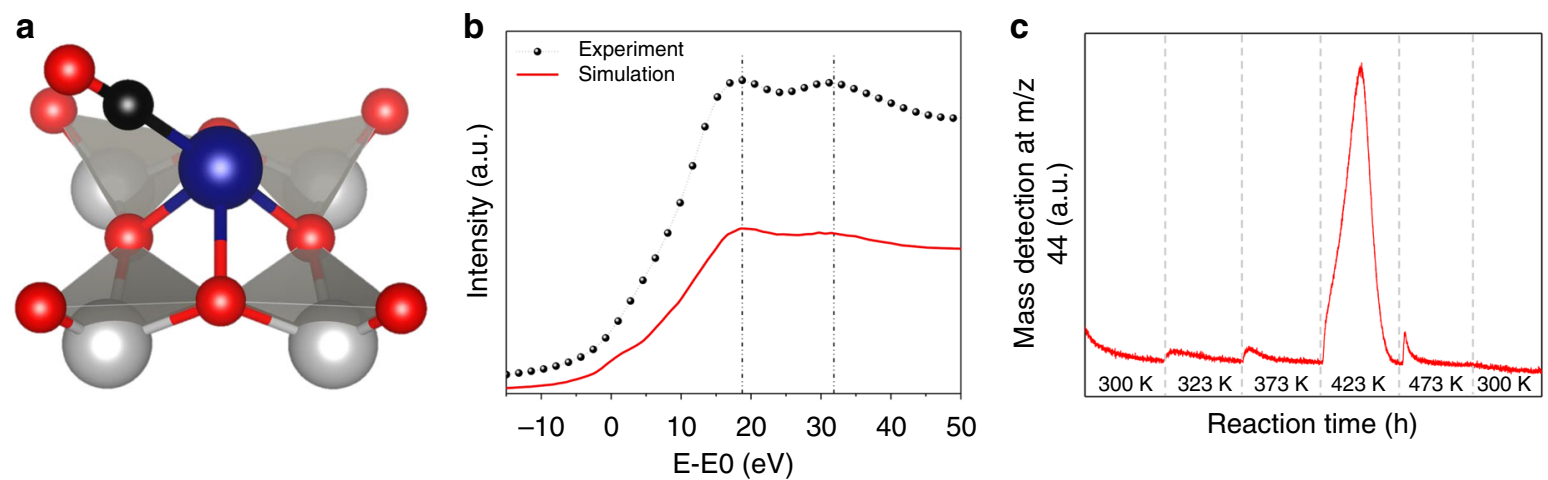

Reaction time (h)
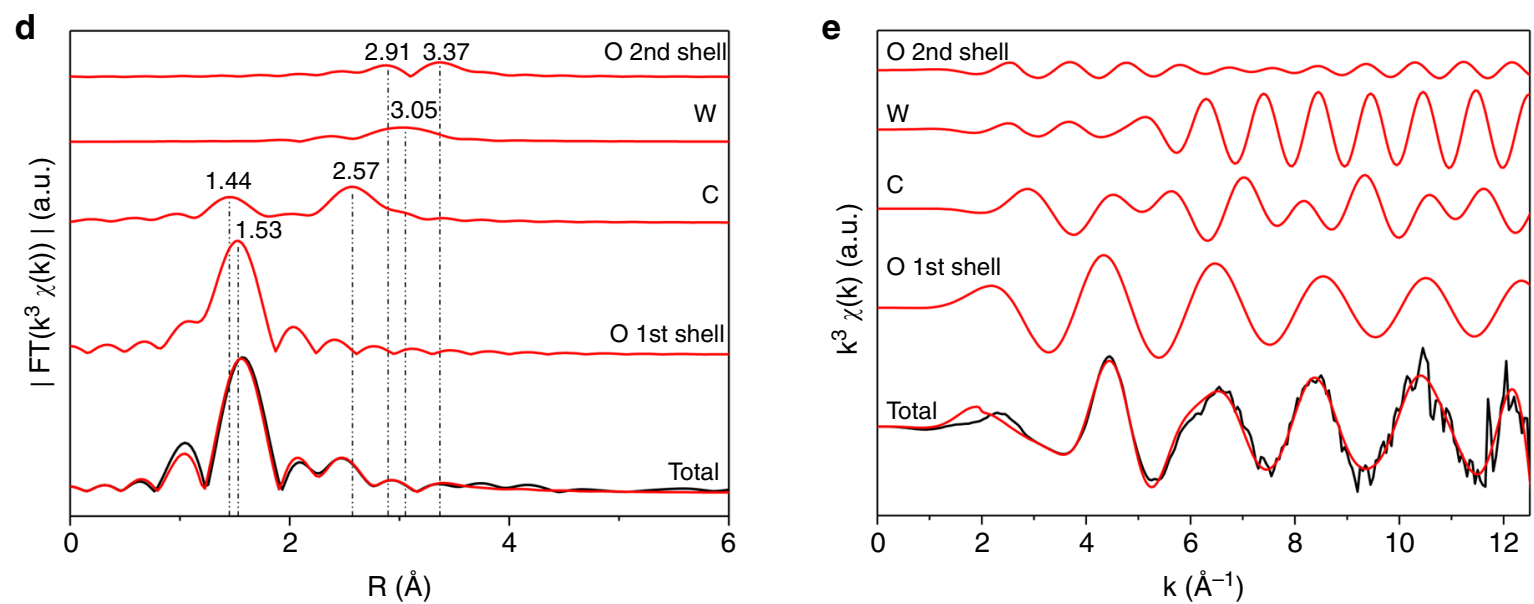

Fig. 3 Re-oxidation of the catalyst under oxygen atmosphere. a DFT-optimized structure of the intermediate of the catalyst under oxidative conditions. Atom colors: W (gray), O (red), C (black), Rh (blue). b best fit for the XANES simulation of the catalyst structure depicted in a. c Temperature dependence of the formation of $\mathrm{CO}_{2}$ during the treatment under $\mathrm{O}_{2}$ as determined by online mass spectrometry. $\mathbf{d}$, e EXAFS analysis of structure $\mathbf{a}$ in $\mathbf{d} \mathrm{R}$ and $\mathbf{e} \mathrm{k}$ space. Curves from bottom to top are the experimental scattering contributions (black) superimposed with the total fitted scattering contributions, Rh-C, $\mathrm{Rh}-\mathrm{O}\left(1^{\text {st }}\right.$ and $2^{\text {nd }}$ shell) and Rh-W scatterings (all in red)

creation on the support and $\mathrm{CO}_{2}$ formation in the gas phase. In contrast, the re-oxidation of $\mathrm{Rh}$ completes at a much higher temperature of $473 \mathrm{~K}$, while the formation of $\mathrm{CO}_{2}$ under oxygen atmosphere is observed only when temperature increases to $423 \mathrm{~K}$, matching very well with the onset temperature of the catalyst. Based on these, the Rh SAC follows an unconventional $\mathrm{M}-\mathrm{vK}$ mechanism where the re-oxidation of metal center and the re-generation of the oxygen site on the support seems to be the rate-controlling step. In an atmosphere containing $\mathrm{CO}$, the adsorption of another molecule of $\mathrm{CO}$ can again be expected to occur rapidly regenerating the catalyst (Eq. 4).

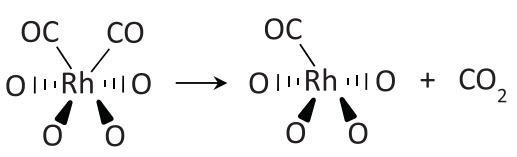

Investigation of the catalyst under steady-state. In addition to the analysis of the catalyst under pure $\mathrm{O}_{2}$ and $\mathrm{CO}$ atmospheres, it is also monitored under a mixture of $\mathrm{O}_{2}$ and $\mathrm{CO}$ at various temperatures. The white line intensity gradually drops and reaches its minimum at $373 \mathrm{~K}$ (Fig. 1e). In the meantime, the preedge feature intensity increases to the same value as observed after treatment of the catalyst under $\mathrm{CO}$. This indicates that the steady-state of the catalyst contains a $\mathrm{Rh}^{+}$species and has the same oxygen vacancy as after reduction with $\mathrm{CO}$. Even after the onset of the CO oxidation (Supplementary Figure 2) at $423 \mathrm{~K}$, those features prevail. These observations are exactly to be expected if the refilling of oxygen vacancy is the rate-limiting step, and are in line with the fact that the reaction has a first order dependence on $\mathrm{O}_{2}$ and zeroth order dependence on $\mathrm{CO}$ as shown earlier ${ }^{44}$.

In situ XPS. Because the observed changes in the oxidation state of tungsten were small according to operando XAS, XPS was chosen as a complimentary technique to investigate the oxidation state of tungsten during the $\mathrm{CO}$ oxidation. The binding energy of the $\mathrm{W} 4 f_{7 / 2}$ peak shifted from 36.1 to $35.6 \mathrm{eV}$ (Fig. 4c) indicating the reduction of $\mathrm{W}$ in the support to occur at close to room temperature. The reduction finishes at $423 \mathrm{~K}$, (Supplementary Figure 13) higher than the full reduction temperature of $\mathrm{Rh}$ in the operando XAS study (373 K), presumably due to the lower CO pressure applied in XPS analysis, or the different catalyst pellet preparation procedures. Those results indicate that the support is actively contributing to the oxidation of $\mathrm{CO}$ and is reduced. The rather small changes in the XPS spectra and the missing formation of separate peaks can be explained by the charge delocalization over the heteropoly acid support ${ }^{60}$. As reported earlier, a change in the tungsten oxidation state between $6^{+}$and $5^{+}$can be indicated by a change in the binding energy of as large as $3 \mathrm{eV}$ (a more detailed analysis is provided in Supplementary Table 2) explaining the average change of $\sim 0.5 \mathrm{eV}$. Under $\mathrm{O}_{2}$ atmosphere, the tungsten species are gradually re-oxidized until $423 \mathrm{~K}$ (Supplementary Figure 14). As observed by operando XAS, the catalyst does not reach the initial oxidation state before temperature reaches $473 \mathrm{~K}$. Exposing the catalyst to a mixture of $\mathrm{O}_{2}$ and $\mathrm{CO}$ leads to an immediate reduction of the tungsten species to 

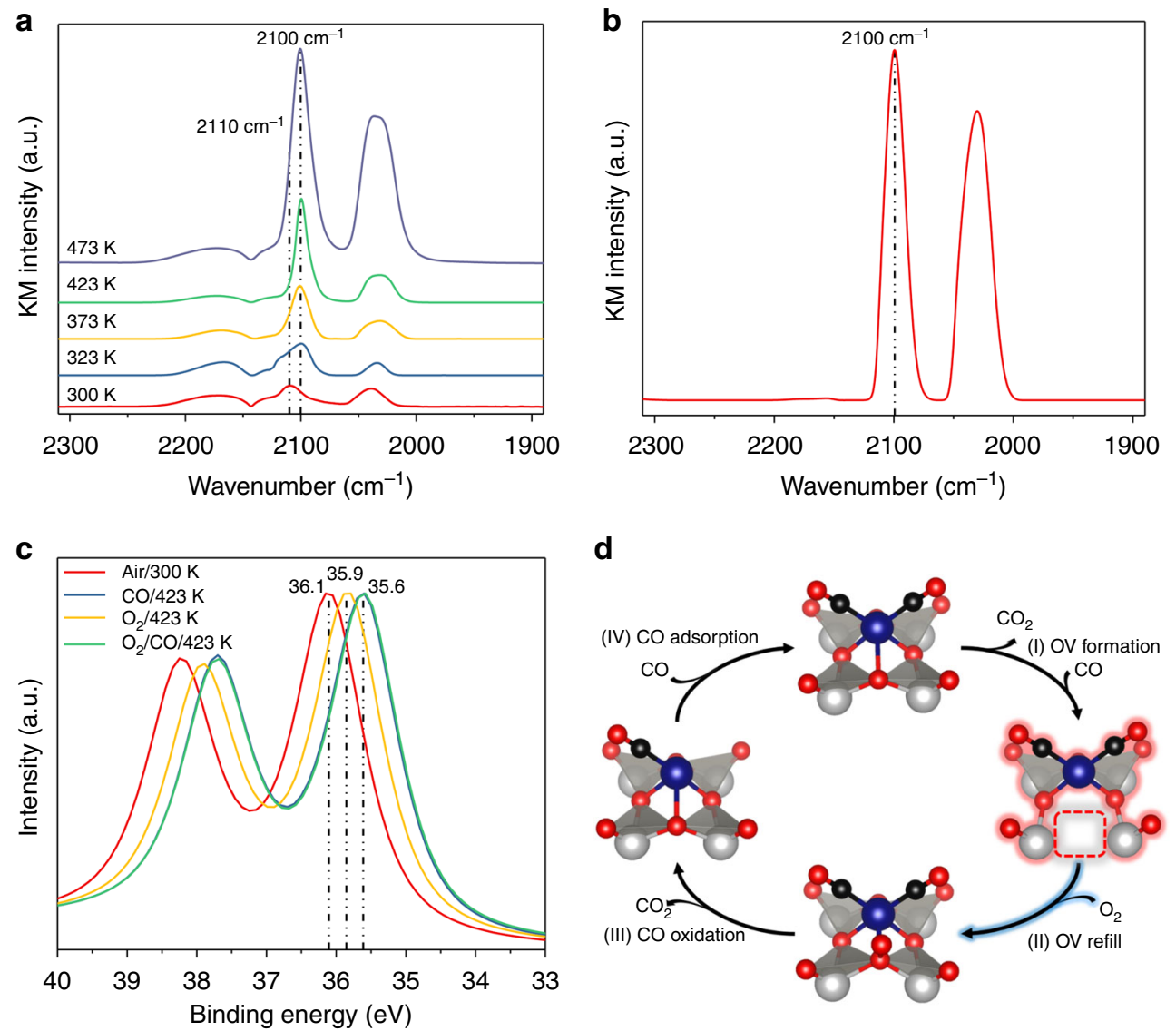

Fig. 4 In situ DRIFT and XPS spectroscopy and proposed reaction cycle. CO DRIFT spectra of a the catalyst under CO at increasing temperatures (from bottom to top) and $\mathbf{b}$ of the catalyst under $\mathrm{CO} / \mathrm{O}_{2}$ at $473 \mathrm{~K}$. c In situ W $4 f_{7 / 2}$ XPS spectra of the catalyst under different gas atmospheres and temperatures. $\mathbf{d}$ Key steps of the proposed reaction mechanism based on in situ spectroscopy; the steady-state catalyst structure and the corresponding rate-controlling step are highlighted. Atom colors: W (gray), O (red), C (black), Rh (blue); OV stands for oxygen vacancy

binding energies of $35.6 \mathrm{eV}$ (Supplementary Figure 15) further confirming the existence of the oxygen vacancy during reaction conditions.

In situ DRIFT spectroscopy. For further consolidation of the adsorbates and the oxidation state changes during the treatment of the catalyst under reaction conditions, in situ DRIFTS experiments were conducted similar to the operando XAS experiments. $\mathrm{CO}$ is a commonly used gas to monitor the dispersion and oxidation state of SACs ${ }^{45}$. Typically, a splitting of the $\mathrm{CO}$ vibration on gem-dicarbonyl $\mathrm{Rh}$ species is observed, which is assigned to the symmetric and asymmetric vibration of two $\mathrm{CO}$ molecules ${ }^{27}$. In the initial state, two $\mathrm{CO}$ frequencies were observed at 2110 and $2039 \mathrm{~cm}^{-1}$, respectively (Fig. 4a), assignable to $\mathrm{Rh}(\mathrm{CO})_{2}{ }^{3+}$ species $^{25}$. Upon exposure to $\mathrm{CO}$ under increasing temperatures, a redshift of the band from 2110 to $2100 \mathrm{~cm}^{-1}$ was observed starting at $323 \mathrm{~K}$, indicating the formation of $\mathrm{Rh}(\mathrm{CO})_{2}{ }^{+}$ species. This is in good alignment with the operando XANES experiments. The same trend is confirmed by ab initio simulations of $\mathrm{CO}$ vibrations. Upon formation of an oxygen vacancy, the predicted CO vibration undergoes a redshift from $2134 \mathrm{~cm}^{-1}$ to $2085 \mathrm{~cm}^{-1}$ (Supplementary Table 1). When the reduced catalyst is treated under a dilute oxygen atmosphere, a partial oxidation is observed at around $323-373 \mathrm{~K}$. However, before complete re-oxidation, CO is completely desorbed (Supplementary Figure 12) suggesting that there is a subsequent removal of $\mathrm{CO}$ from rhodium. Exposing the catalyst to a mixture of $\mathrm{CO}$ and $\mathrm{O}_{2}$ at $473 \mathrm{~K}$ leads to an absorption band at $2100 \mathrm{~cm}^{-1}$ (Fig. $4 \mathrm{~b}$ ), indicating $\mathrm{a} \mathrm{Rh}^{+}$species to be dominant in $\mathrm{CO}$ oxidation, in full agreement with operando XAS data, and thus provide further evidence to support the proposed catalyst cycle (Fig. 4d).

Engineering more efficient CO oxidation catalysts. From above, the reoxidation of the HPA support is the rate-limiting step during the CO oxidation. Designing a catalyst that has a lower barrier for the reoxidation should thus enhance the activity significantly. HPAs have been shown to be redox-tunable by changing the central atom of the whole Keggin unit ( $\mathrm{P}$ or $\mathrm{Si}$ ) or the central atom of the $\mathrm{MO}_{4}$ subunits $(\mathrm{M}=\mathrm{Mo}, \mathrm{W})$ (Fig. 5a). To ensure full atomic dispersion of rhodium for all SACs based on those HPAs we synthesized them following the same procedure as reported previously with a weight loading of $0.2 \%$. ATR-IR (Supplementary Figure 16), Raman spectroscopy (Supplementary Figure 17), and XRD (Supplementary Figure 18) confirms the intact structure of the heteropoly acids after adsorption of rhodium and precipitation as ammonium salt. We also confirmed the atomic dispersion of rhodium on the new catalysts by XAS and CO DRIFTS. CO DRIFTS analysis of the Rh/NPMA catalyst showed the occurrence of two peaks at 2104 and $2034 \mathrm{~cm}^{-1}$. Compared to rhodium on NPTA, the CO absorption wavelengths are slightly shifted towards lower wavenumbers, and rhodium supported on NPMA is reduced at slightly decreased temperatures compared to rhodium on NPTA ( $300 \mathrm{~K}$ vs. $323 \mathrm{~K}$, Fig. 5b). For $0.2 \mathrm{Rh} / \mathrm{NSTA}$ and $0.2 \mathrm{Rh} / \mathrm{NSMA}$, two peaks are observed with positions of the symmetric vibration peaks at 2105 for NSTA and $2097 \mathrm{~cm}^{-1}$ for NSMA, respectively, after a reductive pretreatment (Fig. 5c, d), suggesting the single-atom identity. Similar to the initially studied PTA-based catalyst, we observed a high 
a

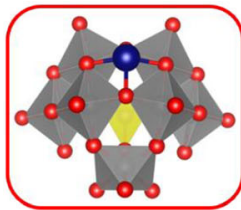

STA

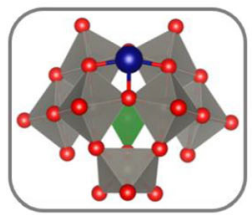

PTA

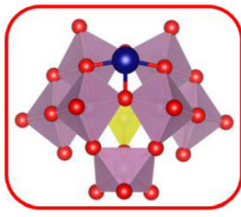

SMA

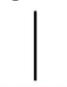

$0.23 \mathrm{~V}$

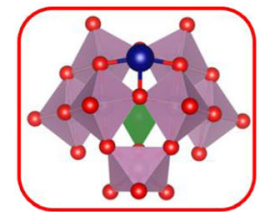

PMA

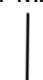

$0.08 \mathrm{~V}$
Oxidation potential
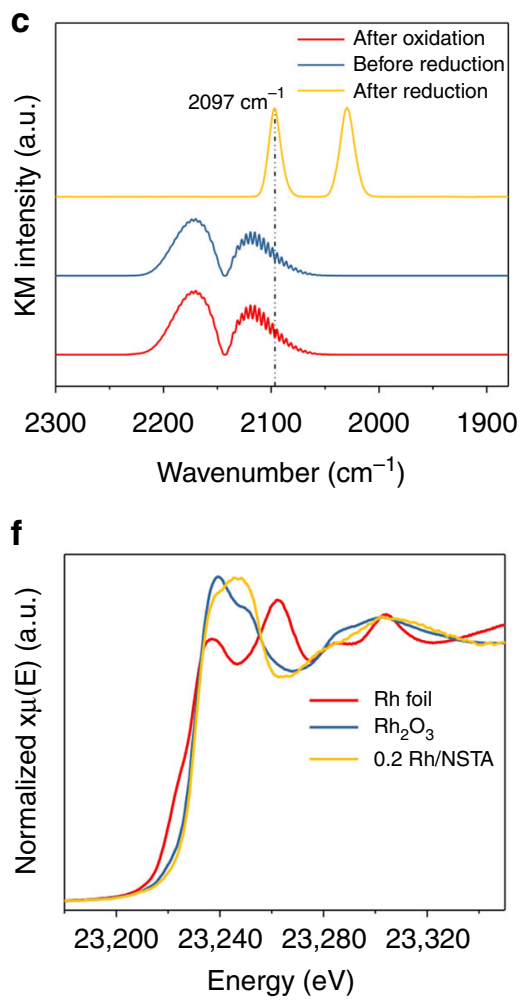

i

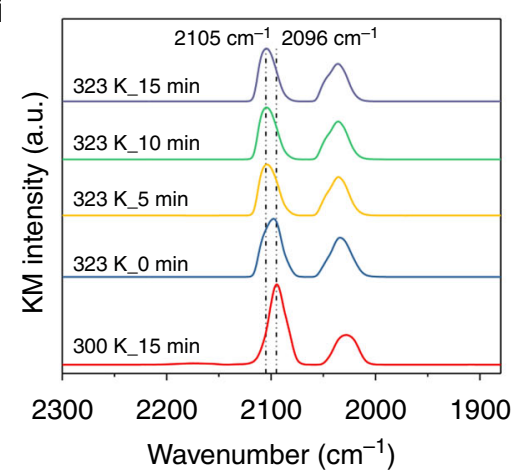

d

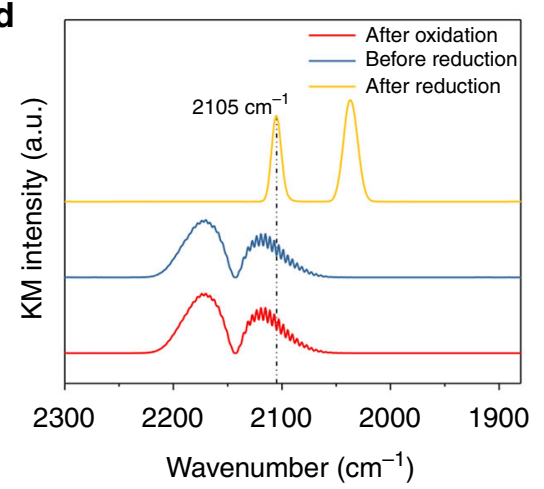

g

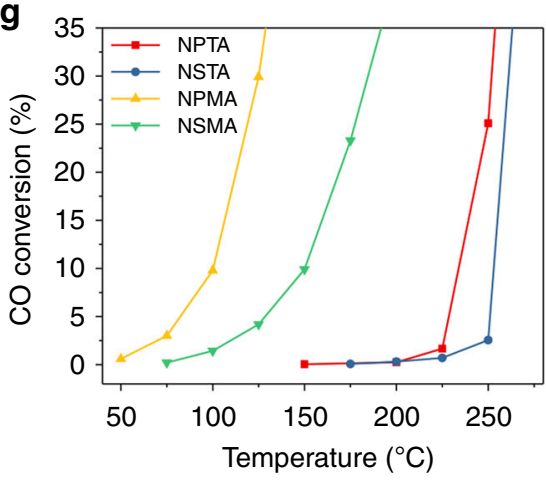

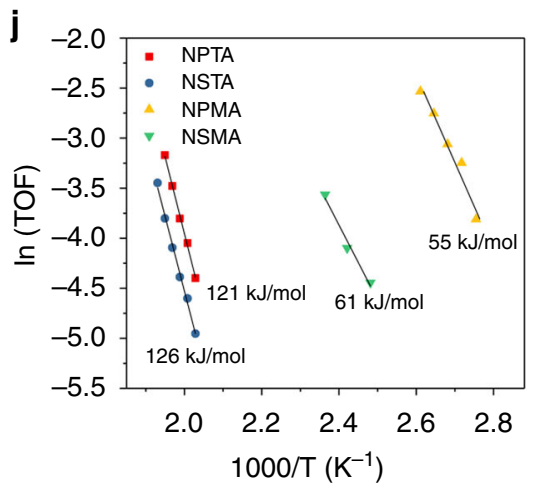

b

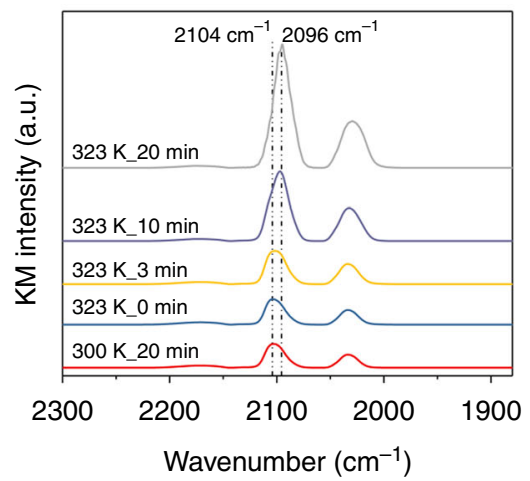

e

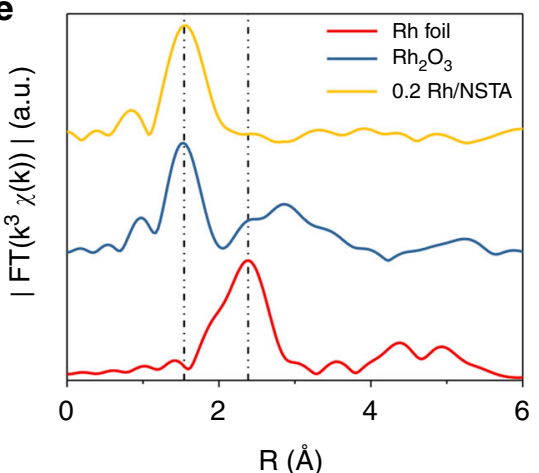

h

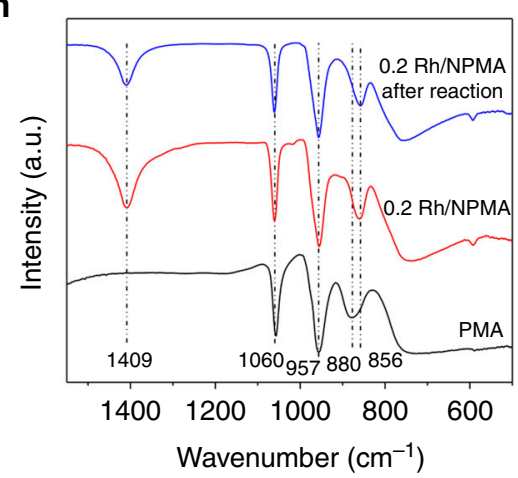

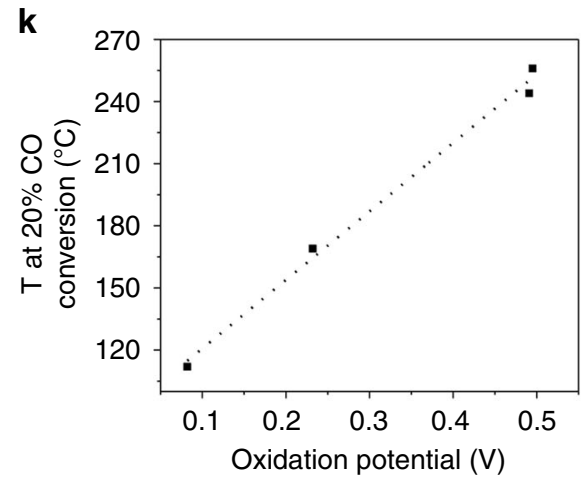

Fig. $5 \mathrm{Ex}$ and in situ characterization and catalytic performance of $0.2 \mathrm{Rh} / \mathrm{NHPA}$. a Design principle for the development of HPA-based SACs based on the oxidation potentials of $4 \mathrm{HPAs}$ (gray indicates the initially studied and red the new catalysts); CO DRIFT for b $0.2 \mathrm{Rh} / \mathrm{NPMA}, \mathbf{c} 0.2 \mathrm{Rh} / \mathrm{NSMA}$ and $\mathbf{d} 0.2$ $\mathrm{Rh} / \mathrm{NSTA}$, oxidation for $(\mathbf{c}, \mathbf{d})$ was carried out at $523 \mathrm{~K}$ for $1 \mathrm{~h}$ under $5 \% \mathrm{O}_{2}$ and reduction was performed using $5 \% \mathrm{CO}$ for 30 min at $373 \mathrm{~K}$; e $\mathrm{k}^{3}$-weighted EXAFS spectra and $\mathbf{f}$ XANES for rhodium foil, $\mathrm{Rh}_{2} \mathrm{O}_{3}$ and $0.2 \mathrm{Rh} / \mathrm{NSTA} ; \mathbf{g}$ Temperature-activity curves for Rh catalysts $(0.2 \mathrm{wt} \%, 100 \mathrm{mg}), \mathrm{GHSV}=$ $24,000 \mathrm{~h}^{-1} 1 \% \mathrm{CO} / 1 \% \mathrm{O}_{2}$, balance Ar; h ATR-IR spectra for PMA, $0.2 \mathrm{Rh} / \mathrm{NPMA}$ before and after CO oxidation up to $300{ }^{\circ} \mathrm{C}$ ( $573 \mathrm{~K}$ ); $\mathbf{i}$ in situ DRIFT spectra for the reoxidation of reduced $0.2 \mathrm{Rh} / \mathrm{NPMA}$ under $5 \% \mathrm{O}_{2}$ atmosphere; $\mathbf{j}$ activation energies of the Rh catalysts (0.2 wt\%) for CO oxidation; k correlation between $\mathrm{T}_{20}$ and oxidation potential of the support 
white line intensity very close to the $\mathrm{Rh}_{2} \mathrm{O}_{3}$ sample and the absence of significant scattering contributions from shells above the first $\mathrm{Rh}-\mathrm{O}$ contribution for $0.2 \mathrm{Rh} / \mathrm{NSTA}$ (Fig. 5e, f). The strong X-ray absorption by molybdenum close to the Rh X-ray edge prevented the XAS analysis for the two molybdenum-based samples. SEM analysis reveals that the morphology of the $\mathrm{Rh}_{1} /$ NPMA catalyst is almost the same as for $\mathrm{Rh}_{1} / \mathrm{NPTA}$ with an EDX pattern revealing homogeneous distribution of $\mathrm{Rh}, \mathrm{Mo}, \mathrm{P}, \mathrm{N}$, and $\mathrm{O}$ whereas $0.2 \mathrm{Rh} / \mathrm{NSTA}$ and $0.2 \mathrm{Rh} / \mathrm{NSMA}$ exhibit a slightly different morphology (Supplementary Figures 19 and 20).

$\mathrm{CO}$ oxidation reactions were performed in a temperature range of $50-300{ }^{\circ} \mathrm{C}(323-573 \mathrm{~K})$ with a GHSV of $24,000 \mathrm{~h}^{-1}$ and a partial pressure of each 0.01 bar for $\mathrm{CO}$ and $\mathrm{O}_{2}$. Distinct differences in the temperature behavior were observed, with the two Mo-based ones showing significant activity even at around $50{ }^{\circ} \mathrm{C}(323 \mathrm{~K})$. The $\mathrm{T}_{20}$ values (temperature at which $20 \% \mathrm{CO}$ conversion is achieved) for NPMA and NSMA are $112^{\circ} \mathrm{C}(385 \mathrm{~K})$ and $169^{\circ} \mathrm{C}(442 \mathrm{~K})$, respectively (Fig. $5 \mathrm{~g}$ ). In comparison, the tungsten-based catalysts only exhibit activity at higher temperatures of $256^{\circ} \mathrm{C}(529 \mathrm{~K})$ for silicotungstic acid (NSTA) and $244^{\circ} \mathrm{C}$ $(517 \mathrm{~K})$ for NPTA (Fig. 5e). ATR-IR and Raman spectroscopy show that even after $\mathrm{CO}$ oxidation reaction at temperatures up to $300{ }^{\circ} \mathrm{C}(573 \mathrm{~K})$, the heteropoly acid structure remains intact (Fig. 5h) and no formation of metal oxides was observed. In situ DRIFTS studies reveal that the reoxidation of reduced rhodium atoms on PMA occurs after being exposed to $\mathrm{O}_{2}$ at temperatures as low as $323 \mathrm{~K}$ for around $5 \mathrm{~min}$ indicated by a shift of the CO vibration from $2096 \mathrm{~cm}^{-1}$ back to $2105 \mathrm{~cm}^{-1}$ (Fig. 5i). The activation energies for $0.2 \mathrm{Rh} / \mathrm{NPTA}$ and $0.2 \mathrm{Rh} / \mathrm{NSTA}$ are very similar at 126 and $121 \mathrm{~kJ} / \mathrm{mol}$ respectively whereas $0.2 \mathrm{Rh} / \mathrm{NPMA}$ exhibits a significantly lower activation energy of $55 \mathrm{~kJ} / \mathrm{mol}$ in accordance with the significantly higher $\mathrm{CO}$ oxidation activity (Fig. 5j). A CO oxidation reaction test with $0.9 \mathrm{Rh} / \mathrm{NPMA}$ reveals an even lower $\mathrm{T}_{20}$ value $\left(82^{\circ} \mathrm{C}, 355 \mathrm{~K}\right)$ as compared to its lower weight loading counterpart (Supplementary Figure 21).

Although it proves difficult to experimentally determine the redox potential of solid catalysts, oxidation potentials of various HPAs have been determined based on electrochemical measurements in solution ${ }^{61}$. We found that the $T_{20}$ values for $\mathrm{CO}$ oxidation indeed correlates very well with the oxidation potentials (Fig. 5k) proving the predictive power derived from the mechanistic understanding of CO oxidation SACs, i.e., the redox tunability of HPAs can be used synergistically to engineer enhanced $\mathrm{CO}$ oxidation catalysts.

\section{Discussion}

Mechanistic elucidations are commonly employed to develop an improved understanding and to guide more intelligent catalyst design. In situ and operando spectroscopic studies represent some of the most promising approaches to investigate the active site and structural dynamics of heterogeneous catalysts under reaction conditions. Particle-based catalysts are well investigated but suffer from spectroscopic contributions from spectator species especially for surface-insensitive techniques such as XAS. SACs offer an enhanced platform as all metal species potentially contribute to the catalytic reaction, but metal oxides supported isolated atoms still suffer from a large heterogeneity. Supports that offer a much more limited number of binding sites with different adsorption energies benefits the homogeneity of metal species and the accuracy of spectroscopic investigations.

In the current work, we have demonstrated via an integrated operando/in situ XAS, XPS, and DRIFTS study that the atomically dispersed $\mathrm{Rh}$-catalyzed $\mathrm{CO}$ oxidation follows a rather unconventional M-vK mechanism with the direct contribution of the heteropoly acid support. All the intermediates shown in
Fig. $4 \mathrm{~d}$ are confirmed by spectroscopy, where $\mathrm{Rh}$ undergoes a cycle between $\mathrm{Rh}^{3+}$ and $\mathrm{Rh}^{+}$and the structure with oxygen vacancy is the dominant working state of the catalyst with the reoxidation of the support as the rate-controlling step. This study adds solid experimental evidence to the general understanding of how $\mathrm{CO}$ and $\mathrm{O}_{2}$ react over a single-atom site that is currently under debate. Stable, atomically dispersed metal sites on structurally well-defined sites particularly suitable for operando/in situ spectroscopy studies can be applied to reveal the reaction mechanisms for a range of different reactions, providing clues on how atomically dispersed catalysts work at a molecular level. As shown here, a combination of spectroscopic techniques, each of which provides information concerning an integral part of $\mathrm{CO}$ oxidation in a SAC system, provides a complete picture of a reaction mechanism. This enhanced mechanistic understanding, then, enables us to engineer supported Rh SACs that exhibit a significantly higher activity compared to the previously reported NPTA-supported Rh SAC.

\section{Methods}

Catalyst synthesis. The precipitated heteropoly acid $\left(\left(\mathrm{NH}_{4}\right)_{3} \mathrm{PW}_{12} \mathrm{O}_{40}\right)$ was synthesized following a coprecipitation method ${ }^{44}$. A solution of $\mathrm{NH}_{4} \mathrm{NO}_{3}(0.075 \mathrm{~mol} / \mathrm{L})$ and $\mathrm{Rh}\left(\mathrm{NO}_{3}\right)_{3}$ (appropriate amount for the desired weight loading), in $30 \mathrm{~mL} \mathrm{DI}$ water was added at $1 \mathrm{~mL} / \mathrm{min}$ to an aqueous solution of heteropoly acid $(30 \mathrm{~mL}$, $0.025 \mathrm{~mol} / \mathrm{L})$ under ice cooling and stirring $(1200 \mathrm{rpm})$ after which a colloidal solution of precipitated Rh/NHPA formed. Under ice cooling and stirring (1200 rpm), the solution was aged for $5 \mathrm{~h}$ and then centrifuged $(4 \mathrm{~min}, 12,200 \times g)$ to obtain a colorless solid. After washing the solid three times with water, the product was dried. For STA and SMA, no precipitate formed after the addition of ammonium salt and thus, water was removed by freeze-drying and the catalyst was used without further washing steps.

Catalyst characterization. We used an iCAP 6000 series inductively-coupled plasma optical emission spectrometry instrument to determine the weight loading of the catalysts after digestion in aqua regia overnight at $353 \mathrm{~K}$. X-ray diffraction pattern were recorded on a Bruker D8 Advance X-ray diffractometer between 5 and $80^{\circ}$. Attenuated total reflection infrared spectroscopy was done using a Thermo Scientific Nicolet iS50 FT-IR spectrometer between 525 and $4000 \mathrm{~cm}^{-1}$ with a spectral resolution of $4 \mathrm{~cm}^{-1}$. Solid state Raman spectroscopy was performed at room temperature on a Horiba Jobin Yvon Modular Raman Spectrometer using a $532 \mathrm{~nm}$ excitation laser, a $\times 100$ objective, $1 \%$ filter and $1200 \mathrm{~mm}^{-1}$ grating. A silicon wafer was used to calibrate the Raman shift. Transmission electron microscopy and scanning electron microscopy images were recorded on a JEM 2100F (JEOL) and on a JEM-6700F (JEOL) microscope, respectively.

Operando and ex situ XAS experiments. Catalyst pellets were made from a thoroughly ground mixture of $300 \mathrm{mg}$ catalyst with $70 \mathrm{mg}$ boron nitride. Sample measurement details are the same as provided in a previous paper ${ }^{62}$. Wavelet analysis was performed using the Morlet wavelet transform procedure with values for $\kappa$ and $\sigma$ of 5 and 1 , respectively ${ }^{63}$. After collecting the spectra at room temperature under ambient conditions, an atmosphere of dilute CO (0.05 bar partial pressure in $\mathrm{He}$ ) was applied in a high-temperature operando cell specifically designed for measurements in the fluorescence mode. Dilute $\mathrm{O}_{2}$ was introduced at a partial pressure of 0.07 bar in He. After each measurement (duration of around $1 \mathrm{~h}$ ), the catalyst was heated up rapidly within around $10 \mathrm{~min}$ and we waited for the temperature to reach a steady state (around $10 \mathrm{~min}$ ) upon which another measurement was started. During the catalyst treatment with the mixed gas atmosphere $\left(\mathrm{CO}+\mathrm{O}_{2}, 0.025\right.$ bar partial pressure each in $\left.\mathrm{He}\right)$, the reaction was performed in an excess of reactant gases to ensure that the reaction is conducted under purely kinetic limitations (Supplementary Figure 1). A similar procedure was used for the tungsten XAS measurements but another operando cell designed for measurements in the transmission mode was employed and the time for each measurement reduced to $15-20 \mathrm{~min}$.

Ex situ Rh K-edge XAS measurements were carried out at a public beamline, BL14B2, SPring-8 (Japan Synchrotron Radiation Research Institute, Hyogo, Japan).

DRIFTS experiments. In situ diffuse reflectance infrared Fourier transform (DRIFT) spectra were recorded using an iS50 FT-IR spectrometer with a mercurycadmium-telluride (MCT) detector and a Praying Mantis ${ }^{\mathrm{TM}}$ high-temperature reaction chamber with zinc selenide windows. For all spectra, 32 scans with a resolution of $4 \mathrm{~cm}^{-1}$ were recorded in a range of $1700-2350 \mathrm{~cm}^{-1}$. Powder samples were placed in a reaction cell (Harricks HV-DR2) and background spectra were taken under a flow of inert gas at different temperatures. All gases and gas mixtures were introduced at $40 \mathrm{~mL} / \mathrm{min}$ and the partial pressures were 0.025 bar for $\mathrm{CO}$ and $\mathrm{O}_{2}$ for the individual gases and 0.025 bar each for the mixture of $\mathrm{CO}$ and $\mathrm{O}_{2}$ 
(balance Ar). For the oxygen treatment of the catalyst, the catalyst was subjected to a reductive treatment under dilute $\mathrm{CO}$ for $20 \mathrm{~min}$ at room temperature prior to the introduction of dilute $\mathrm{O}_{2}$

Ex situ measurements were performed using a similar procedure as described above but after collecting background spectra under nitrogen atmosphere, dilute $\mathrm{CO}$ was introduced until a steady state was reached upon which nitrogen gas was introduced again to remove gas phase $\mathrm{CO}$. For the oxidative treatment of the 0.2 $\mathrm{Rh} / \mathrm{NSTA}$ and $0.2 \mathrm{Rh} / \mathrm{NSMA}$ catalysts, the catalyst powder was treated under $5 \%$ oxygen at $523 \mathrm{~K}$ for $1 \mathrm{~h}$ and cooled down to room temperature after which the CO treatment was done as mentioned above. Reductive treatment was done using 5\% $\mathrm{CO}$ at $323 \mathrm{~K}$ for $30 \mathrm{~min}$ after which the catalyst was cooled back to room temperature and gas phase $\mathrm{CO}$ was removed by flushing nitrogen.

In situ XPS experiments. Catalyst pellets were produced by thoroughly mixing and pressing $200 \mathrm{mg}$ catalyst, $50 \mathrm{mg}$ boron nitride, and $2 \mathrm{mg}$ graphene nanoplatelets $\left(750 \mathrm{~m}^{2} / \mathrm{g}\right)$ as internal standard. All binding energies were adjusted based on the most intense C $1 \mathrm{~s}$ peak at $284.5 \mathrm{eV}$. The in situ XPS experiments were performed in the laboratory-based SPECS Phoibos 150 NAP-XPS (near ambient pressure XPS) package equipped with a twin anode X-ray source (SPECS XR50, Al $\mathrm{Ka}, \mathrm{h} v=1486.6 \mathrm{eV} ; \mathrm{Mg} \mathrm{Ka}, \mathrm{h} v=1253.6 \mathrm{eV}$ ) with a base pressure at $5 \times 10^{-10}$ mbar. Two independent gas lines were connected to the NAP cell to let gas fill the cell to several mbar from ultra-high vacuum effectively in $2 \mathrm{~min}$. The catalyst was loaded near the $300 \mu \mathrm{m}$ nozzle of the NAP cell and illuminated to the X-ray through a $100 \mathrm{~nm}$ SiN window. The temperature-programmed mode was carried out in the NAP-XPS measurements: 0.5 mbar CO gas was introduced to the cell at room temperature and then the cell was heated from $300 \mathrm{~K}$ to $473 \mathrm{~K}$ in 5 steps. After that, the system was cooled down to room temperature using liquid nitrogen cooled nitrogen gas and the $\mathrm{CO}$ gas was pumped out to UHV. $0.5 \mathrm{mbar}_{2}$ gas was introduced to the system as following in the same procedures and the catalyst was exposed to the mixture of $\mathrm{CO}$ and $\mathrm{O}_{2}$ (with $0.5 \mathrm{mbar}$ partial pressure each) gases at different temperatures. All the measurements were taken until the pressure and temperature were stable to reach the equilibrium conditions of the surface. The core-level spectra of $\mathrm{W} 4 f_{7 / 2}$ were measured by using the $\mathrm{Al} \mathrm{Ka}$ source with kinetic energies at around $1450 \mathrm{eV}$. The pass energy was set at $30 \mathrm{eV}$ for each measurement.

DFT calculations. Calculations were carried out with the local meta-GGA correlation functional M06L ${ }^{64}$ using Gaussian09 D.01 as has been employed for polyoxometalates $^{65}$ earlier. All geometry optimizations and frequency calculations were done using the basis sets $6-31 \mathrm{G}^{* * 66}$ for the lighter elements $(\mathrm{C}, \mathrm{O}, \mathrm{P})$ and the pseudopotential basis sets LANL2DZ ${ }^{67}$ for tungsten and rhodium. Each obtained optimized structure was checked to have the right number of imaginary frequencies. Images of the geometry-optimized structures were created using VESTA. CO vibrations were predicted using the same functional and basis set with a scaling factor of $0.972^{68}$

Simulations of XANES spectra. The Rh K-edge XANES simulations were conducted using the ab initio FEFF 8 program ${ }^{69}$. The structural models from DFT calculations were used for the atomic coordinates in the FEFF input cards. A slight modification $(0-2 \%)$ of the bond distances using the RMULTIPLIER card was allowed to optimize the XANES simulations. The simulated XANES spectra were plotted using the normalized E0 scale (E-E0). The E0 value of the simulated XANES was set at $0 \mathrm{eV}$ by calibrating the shift of calculated Fermi levels from the FEFF SCF calculations.

CO oxidation reaction. $\mathrm{CO}$ oxidation reactions were performed in a stainless steel tubular plug flow reactor. A volume of $100 \mathrm{mg}$ catalyst was charged into the reactor surrounded by quartz wool and the reactor was heated inside a tube furnace with an external thermocouple. Catalysts were pretreated under $5 \% \mathrm{O}_{2}$ in $\mathrm{Ar}$ for $30 \mathrm{~min}$ at $250^{\circ} \mathrm{C}(523 \mathrm{~K})$ with a heating rate of $5 \mathrm{~K} / \mathrm{min}$. A mixture of $2.5 \% \mathrm{CO}$ and $2.5 \%$ $\mathrm{O}_{2}$ balanced with Ar was introduced and the tube was heated to the desired starting temperature. Steady-state conversion and yield measurements were performed after reaching steady-state after $30 \mathrm{~min}$ reaction using an Agilent 7890B gas chromatograph with a TCD detector. For activation energy measurements, the $\mathrm{CO}$ conversion was kept below $25 \%$.

\section{Data availability}

The data that support the findings of this study are available from the corresponding authors upon reasonable request.

Received: 6 September 2018 Accepted: 15 February 2019

Published online: 22 March 2019

\section{References}

1. Flytzani-Stephanopoulos, M. \& Gates, B. C. Atomically dispersed supported metal catalysts. Annu. Rev. Chem. Biomol. Eng. 3, 545-574 (2012).
2. Yang, X.-F. et al. Single-atom catalysts: a new frontier in heterogeneous catalysis. Acc. Chem. Res. 46, 1740-1748 (2013).

3. Liu, J. Catalysis by supported single metal atoms. ACS Catal. 7, 34-59 (2017).

4. Zhu, C., Fu, S., Shi, Q., Du, D. \& Lin, Y. Single-atom electrocatalysts. Angew. Chem. Int. Ed. 56, 13944-13960 (2017).

5. Kim, J., Kim, H. E. \& Lee, H. Single-atom catalysts of precious metals for electrochemical reactions. ChemSusChem 11, 104-113 (2018).

6. Hülsey, M. J., Zhang, J. \& Yan, N. Harnessing the wisdom in colloidal chemistry to make stable single-atom catalysts. Adv. Mater. 30, 1802304 (2018).

7. Chen, Y. et al. Single-atom catalysts: synthetic strategies and electrochemical applications. Joule 2, 1242-1264 (2018).

8. Wang, A., Li, J. \& Zhang, T. Heterogeneous single-atom catalysis. Nat. Rev. Chem. 2, 65-81 (2018).

9. Moses-DeBusk, M. et al. CO oxidation on supported single Pt atoms: experimental and ab initio density functional studies of $\mathrm{CO}$ interaction with $\mathrm{Pt}$ atom on $\theta-\mathrm{Al}_{2} \mathrm{O}_{3}(010)$ surface. J. Am. Chem. Soc. 135, 12634-12645 (2013).

10. Bruix, A. et al. Maximum noble-metal efficiency in catalytic materials: atomically dispersed surface platinum. Angew. Chem. Int. Ed. 53, 10525-10530 (2014)

11. Lucci, F. R. et al. Selective hydrogenation of 1,3-butadiene on platinum-copper alloys at the single-atom limit. Nat. Commun. 6, 8550 (2015).

12. Jones, J. et al. Thermally stable single-atom platinum-on-ceria catalysts via atom trapping. Science 353, 150-154 (2016).

13. Yang, S., Kim, J., Tak, Y. J., Soon, A. \& Lee, H. Single-atom catalyst of platinum supported on titanium nitride for selective electrochemical reactions. Angew. Chem. Int. Ed. 55, 2058-2062 (2016).

14. Lin, L. et al. Low-temperature hydrogen production from water and methanol using Pt/a-MoC catalysts. Nature 544, 80 (2017).

15. Liu, J. et al. High performance platinum single atom electrocatalyst for oxygen reduction reaction. Nat. Commun. 8, 15938 (2017).

16. Zhang, $\mathrm{Z}$. et al. Thermally stable single atom $\mathrm{Pt} / \mathrm{m}-\mathrm{Al}_{2} \mathrm{O}_{3}$ for selective hydrogenation and CO oxidation. Nat. Commun. 8, 16100 (2017).

17. Zhang, L., Han, L., Liu, H., Liu, X. \& Luo, J. Potential-cycling synthesis of single platinum atoms for efficient hydrogen evolution in neutral media. Angew. Chem. Int. Ed. 56, 13694-13698 (2017).

18. Kim, J. et al. Highly durable platinum single-atom alloy catalyst for electrochemical reactions. Adv. Energy Mater. 8, 1701476 (2018).

19. Vilé, G. et al. A stable single-site palladium catalyst for hydrogenations. Angew. Chem. Int. Ed. 54, 11265-11269 (2015).

20. Yan, $\mathrm{H}$. et al. Single-atom $\mathrm{Pd}_{1} /$ Graphene catalyst achieved by atomic layer deposition: remarkable performance in selective hydrogenation of 1,3Butadiene. J. Am. Chem. Soc. 137, 10484-10487 (2015).

21. Xin, P. et al. Revealing the active species for aerobic alcohol oxidation by using uniform supported palladium catalysts. Angew. Chem. Int. Ed. 57, 4642-4646 (2018).

22. Peterson, E. J. et al. Low-temperature carbon monoxide oxidation catalysed by regenerable atomically dispersed palladium on alumina. Nat. Commun. $\mathbf{5}$, 4885 (2014).

23. Chen, Z. et al. A heterogeneous single-atom palladium catalyst surpassing homogeneous systems for Suzuki coupling. Nat. Nanotechnol. 13, 702-707 (2018).

24. Wang, L. et al. Catalysis and in situ studies of $\mathrm{Rh}_{1} / \mathrm{Co}_{3} \mathrm{O}_{4}$ nanorods in reduction of NO with $\mathrm{H}_{2}$. ACS Catal. 3, 1011-1019 (2013).

25. Lang, R. et al. Hydroformylation of olefins by a rhodium single-atom catalyst with activity comparable to $\mathrm{RhCl}\left(\mathrm{PPh}_{3}\right)_{3}$. Angew. Chem. Int. Ed. 128, 16288-16292 (2016)

26. Ghosh, T. K. \& Nair, N. N. $\mathrm{Rh}_{1} / \gamma-\mathrm{Al}_{2} \mathrm{O}_{3}$ single-atom catalysis of $\mathrm{O}_{2}$ activation and $\mathrm{CO}$ oxidation: mechanism, effects of hydration, oxidation state, and cluster size. Chem CatChem 5, 1811-1821 (2013).

27. Matsubu, J. C., Yang, V. N. \& Christopher, P. Isolated metal active site concentration and stability control catalytic $\mathrm{CO}_{2}$ reduction selectivity. J. Am. Chem. Soc. 137, 3076-3084 (2015).

28. Shan, J., Li, M., Allard, L. F., Lee, S. \& Flytzani-Stephanopoulos, M. Mild oxidation of methane to methanol or acetic acid on supported isolated rhodium catalysts. Nature 551, 605 (2017).

29. Kwon, Y., Kim, T. Y., Kwon, G., Yi, J. \& Lee, H. Selective activation of methane on single-atom catalyst of rhodium dispersed on zirconia for direct conversion. J. Am. Chem. Soc. 139, 17694-17699 (2017).

30. Wang, L. et al. Supported rhodium catalysts for ammonia-borane hydrolysis: dependence of the catalytic activity on the highest occupied state of the single rhodium atoms. Angew. Chem. Int. Ed. 56, 4712-4718 (2017).

31. Tang, Y. et al. Single rhodium atoms anchored in micropores for efficient transformation of methane under mild conditions. Nat. Commun. 9, 1231 (2018).

32. Yang, M., Allard, L. F. \& Flytzani-Stephanopoulos, M. Atomically dispersed $\mathrm{Au}-(\mathrm{OH})_{\mathrm{x}}$ species bound on titania catalyze the low-temperature water-gas shift reaction. J. Am. Chem. Soc. 135, 3768-3771 (2013). 
33. Liu, J.-C., Wang, Y.-G. \& Li, J. Toward rational design of oxide-supported single-atom catalysts: atomic dispersion of gold on ceria. J. Am. Chem. Soc. 139, 6190-6199 (2017).

34. Deng, D. et al. A single iron site confined in a graphene matrix for the catalytic oxidation of benzene at room temperature. Sci. Adv. 1, e1500462 (2015).

35. Yang, H. B. et al. Atomically dispersed $\mathrm{Ni}(\mathrm{I})$ as the active site for electrochemical $\mathrm{CO}_{2}$ reduction. Nat. Energy 3, 140-147 (2018).

36. Han, Y. et al. Hollow N-doped carbon spheres with isolated cobalt single atomic sites: superior electrocatalysts for oxygen reduction. J. Am. Chem. Soc. 139, 17269-17272 (2017).

37. Yin, P. et al. Single cobalt atoms with precise $\mathrm{N}$-coordination as superior oxygen reduction reaction catalysts. Angew. Chem. Int. Ed. 55, 10800-10805 (2016).

38. Liu, G. et al. $\mathrm{MoS}_{2}$ monolayer catalyst doped with isolated Co atoms for the hydrodeoxygenation reaction. Nat. Chem. 9, 810-816 (2017).

39. Chao, T. et al. Atomically dispersed copper-platinum dual sites alloyed with palladium nanorings catalyze the hydrogen evolution reaction. Angew. Chem. Int. Ed. 56, 16047-16051 (2017).

40. Qiao, B. et al. Single-atom catalysis of $\mathrm{CO}$ oxidation using $\mathrm{Pt}_{1} / \mathrm{FeO}_{\mathrm{x}}$. Nat. Chem. 3, 634-641 (2011).

41. Liang, J.-X. et al. Theoretical and experimental investigations on single-atom catalysis: $\mathrm{Ir}_{1} / \mathrm{FeOx}$ for $\mathrm{CO}$ oxidation. J. Phys. Chem. C. 118, 21945-21951 (2014).

42. Ding, K. et al. Identification of active sites in CO oxidation and water-gas shift over supported Pt catalysts. Science 350, 189-192 (2015).

43. Wang, C. et al. Water-mediated Mars-Van Krevelen mechanism for CO oxidation on ceria supported single-atom $\mathrm{Pt}_{1}$ catalyst. ACS Catal. 7, 887-891 (2017).

44. Zhang, B., Asakura, H. \& Yan, N. Atomically dispersed rhodium on selfassembled phosphotungstic acid: structural features and catalytic $\mathrm{CO}$ oxidation properties. Ind. Eng. Chem. Res. 56, 3578-3587 (2017).

45. DeRita, L. et al. Catalyst architecture for stable single atom dispersion enables site-specific spectroscopic and reactivity measurements of $\mathrm{CO}$ adsorbed to $\mathrm{Pt}$ atoms, oxidized Pt clusters, and metallic Pt clusters on $\mathrm{TiO}_{2}$. J. Am. Chem. Soc. 139, 14150-14165 (2017).

46. Zhou, X. et al. Unraveling charge state of supported Au single-atoms during CO oxidation. J. Am. Chem. Soc. 140, 554-557 (2018).

47. Jeong, H. et al. Fully dispersed Rh ensemble catalyst to enhance lowtemperature activity. J. Am. Chem. Soc. 140, 9558-9565 (2018).

48. Wang, Y., Zhang, X., Cheng, C. \& Yang, Z. TiC supported single-atom platinum catalyst for $\mathrm{CO}$ oxidation: a density functional theory study. Appl. Surf. Sci. 453, 159-165 (2018).

49. $\mathrm{Lu}, \mathrm{Z}$. et al. A promising single atom catalyst for $\mathrm{CO}$ oxidation: Ag on boron vacancies of h-BN sheets. Phys. Chem. Chem. Phys. 19, 16795-16805 (2017).

50. Zhang, S. et al. In-situ studies of nanocatalysis. Acc. Chem. Res. 46, 1731-1739 (2013).

51. Malta, G. et al. Identification of single-site gold catalysis in acetylene hydrochlorination. Science 355, 1399-1403 (2017).

52. Zhang, B. et al. Stabilizing a platinum 1 single-atom catalyst on supported phosphomolybdic acid without compromising hydrogenation activity. Angew. Chem. Int. Ed. 55, 8319-8323 (2016).

53. Getty, K., Delgado-Jaime, M. U. \& Kennepohl, P. Assignment of pre-edge features in the Ru K-edge $\mathrm{x}$-ray absorption spectra of organometallic ruthenium complexes. Inorg. Chim. Acta 361, 1059-1065 (2008).

54. Nishiumi, M., Miura, H., Wada, K., Hosokawa, S. \& Inoue, M. Active ruthenium catalysts based on phosphine-modified $\mathrm{Ru} / \mathrm{CeO}_{2}$ for the selective addition of carboxylic acids to terminal alkynes. ACS Catal. 2, 1753-1759 (2012).

55. Hosokawa, S. et al. Oxidation characteristics of $\mathrm{Ru} / \mathrm{CeO}_{2}$ catalyst. Appl. Catal., A 288, 67-73 (2005).

56. van Bokhoven, J. A. et al. Activation of oxygen on gold/alumina catalysts: in situ high-energy-resolution fluorescence and time-resolved X-ray spectroscopy. Angew. Chem. Int. Ed. 118, 4767-4770 (2006).

57. Filez, M., Redekop, E. A., Poelman, H., Galvita, V. V. \& Marin, G. B. Advanced elemental characterization during Pt-In catalyst formation by wavelet transformed X-ray absorption spectroscopy. Anal. Chem. 87, 3520-3526 (2015).

58. Zhang, L.-L., Sun, M.-J. \& Liu, C.-G. CO oxidation on the phosphotungstic acid supported Rh single-atom catalysts via $\mathrm{Rh}$-assisted Mans-van Krevelen mechanism. Mol. Catal. 462, 37-45 (2019).

59. Dalba, G., Fornasini, P., Grisenti, R. \& Purans, J. Sensitivity of extended X-rayabsorption fine structure to thermal expansion. Phys. Rev. Lett. 82, 4240 (1999).

60. Kozhevnikov, I. V. Friedel-Crafts acylation and related reactions catalysed by heteropoly acids. Appl. Catal., A 256, 3-18 (2003).

61. Song, I. K. \& Barteau, M. A. Redox properties of Keggin-type heteropolyacid (HPA) catalysts: effect of counter-cation, heteroatom, and polyatom substitution. J. Mol. Catal. A Chem. 212, 229-236 (2004).
62. Asakura, $\mathrm{H}$. et al. Dynamic behavior of Rh species in $\mathrm{Rh} / \mathrm{Al} 2 \mathrm{O} 3$ model catalyst during three-way catalytic reaction: an operando X-ray absorption spectroscopy study. J. Am. Chem. Soc. 140, 176-184 (2018).

63. Funke, H., Scheinost, A. \& Chukalina, M. Wavelet analysis of extended X-ray absorption fine structure data. Phys. Rev. B 71, 094110 (2005).

64. Zhao, Y. \& Truhlar, D. G. A new local density functional for main-group thermochemistry, transition metal bonding, thermochemical kinetics, and noncovalent interactions. J. Chem. Phys. 125, 194101 (2006).

65. Liu, C.-G., Jiang, M.-X. \& Su, Z.-M. Computational study on $\mathrm{M}_{1} / \mathrm{POM}$ singleatom catalysts $\left(\mathrm{M}=\mathrm{Cu}, \mathrm{Zn}, \mathrm{Ag}\right.$, and $\left.\mathrm{Au} ; \mathrm{POM}=\left[\mathrm{PW}_{12} \mathrm{O}_{40}\right]^{3-}\right)$ : metal-support interactions and catalytic cycle for alkene epoxidation. Inorg. Chem. 56, 10496-10504 (2017).

66. Ditchfield, R., Hehre, W. J. \& Pople, J. A. Self-consistent molecular-orbital methods. IX. An extended Gaussian-type basis for molecular-orbital studies of organic molecules. J. Chem. Phys. 54, 724-728 (1971).

67. Hay, P. J. \& Wadt, W. R. Ab initio effective core potentials for molecular calculations. Potentials for $\mathrm{K}$ to Au including the outermost core orbitals. J. Chem. Phys. 82, 299-310 (1985).

68. Assefa, M. K., Devera, J. L., Brathwaite, A. D., Mosley, J. D. \& Duncan, M. A Vibrational scaling factors for transition metal carbonyls. Chem. Phys. Lett. 640, 175-179 (2015).

69. Ankudinov, A. L., Ravel, B., Rehr, J. J. \& Conradson, S. D. Real-space multiplescattering calculation and interpretation of X-ray-absorption near-edge structure. Phys. Rev. B 58, 7565-7576 (1998).

\section{Acknowledgements}

We thank the NUS Flagship Green Energy Programme for the financial support. XAS measurements were performed at public XAS beamlines, BL01B1 and BL14B2, SPring- 8 (Japan Synchrotron Radiation Research Institute, Hyogo, Japan) under the approval of JASRI (Proposal No. 2017A1256 \& 2018B0949). W.C. acknowledges the funding support from National Natural Science Foundation of China (NSFC 91645102), Singapore National Research Foundation under the grant of NRF2017NRF-NSFC001-007. P.Z. thanks NSERC Canada for financial support. Z.W. was supported by U.S. Department of Energy, Office of Science, Office of Basic Energy Sciences, Chemical Sciences, Geosciences, and Biosciences Division.

\section{Author Contributions}

N.Y. conceived and supervised the project. M.J.H., B.Z., H.A., T.T. and N.Y. designed the experiments. M.J.H., B.Z. and H.A. synthesized the catalysts and performed and analyzed the in situ DRIFTS and operando XAS experiments. M.J.H. and B.Z. conducted the CO oxidation reactions, the FT-IR and Raman spectroscopy experiments and microscopy. Z.M. and W.C. conducted in situ XPS experiments. M.J.H., D.A.D. and P.Z. performed the DFT calculations and ab initio XANES predictions. M.J.H., B.Z., H.A., P.Z., Z.W. and N.Y. contributed to writing the manuscript.

\section{Additional information}

Supplementary Information accompanies this paper at https://doi.org/10.1038/s41467019-09188-9.

Competing interests: The authors declare no competing interests.

Reprints and permission information is available online at http://npg.nature.com/ reprintsandpermissions/

Journal Peer Review Information: Nature Communications thanks Dave Willock, and other anonymous reviewer(s) for their contribution to the peer review of this work. Peer reviewer reports are available.

Publisher's note: Springer Nature remains neutral with regard to jurisdictional claims in published maps and institutional affiliations.

Open Access This article is licensed under a Creative Commons Attribution 4.0 International License, which permits use, sharing adaptation, distribution and reproduction in any medium or format, as long as you give appropriate credit to the original author(s) and the source, provide a link to the Creative Commons license, and indicate if changes were made. The images or other third party material in this article are included in the article's Creative Commons license, unless indicated otherwise in a credit line to the material. If material is not included in the article's Creative Commons license and your intended use is not permitted by statutory regulation or exceeds the permitted use, you will need to obtain permission directly from the copyright holder. To view a copy of this license, visit http://creativecommons.org/ licenses/by/4.0/.

(C) The Author(s) 2019 